\title{
O ESPAÇO PÚBLICO E A CIDADANIA: CONTRIBUIÇÕES DE HANNAH ARENDT
}

\author{
PUBLIC SPACE AND CITIZENSHIP: HANNAH ARENDT'S CONTRIBUTIONS
}

Evandson Paiva Ferreira*

\begin{abstract}
RESUMO:
Neste artigo tomo como objeto de investigação a noção de espaço público na obra da filósofa Hannah Arendt, questão central de seu pensamento, procurando estabelecer uma relação crítica entre sua obra e o contexto brasileiro, vislumbrando uma possível contribuição para pensar a nossa realidade política. Num primeiro momento destaco a formação do pensamento de Arendt, suas influências intelectuais e como, ao pôr em questão sua experiência de vida, criou novas categorias políticas que dessem conta das novas realidades do século XX. Em seguida destaco a constituição do conceito de espaço público, que terá no pensamento clássico grego a arkhé da vida política, baseada na fala e ação de sujeitos que têm na vida coletiva seu télos. Mostro ainda a crítica arendtiana à modernidade, como época de empobrecimento da vida política e confusão entre o mundo público e o mundo privado, tendo neste a razão de ser da sociedade. E, por fim, interrogo a importância e as contribuições da reflexão política de Arendt para pensar os desafios da realidade política brasileira. Espaço público, cidadania, direitos humanos, cultura cívica, republicanismo são noções de Arendt, cuja realização está posta no horizonte da sociedade brasileira com vista ao fortalecimento de nossa democracia.
\end{abstract}

PALAVRAS-CHAVE: Sociedade. Política. Espaço público. Democracia. Cidadania.

\section{ABSTRACT:}

In this article, the object of investigation is the notion of public space in the work of the philosopher Hannah Arendt, which is a central issue in her thought. I seek to establish a critical relationship between her work and the Brazilian context, aiming at a possible contribution to reflect on our political reality. Firstly, I underline the formation of Arendt's thought, her intellectual influences, and by questioning her life experience, how she created new political categories able to consider the new realities of the twentieth century. Next, I highlight the formation of the concept of public space that will have in classical Greek thought the arche of political life, based on speech and action from individuals who see their telos in the collective life. I also show the Arendtian criticism of modernity as an epoch of impoverishment of political life and confusion between public and private spheres, having on the latter the very reason for society. Finally, I question the importance and contributions of Arendt's political thought to reflect on the challenges of Brazilian political reality. Public space, citizenship, human rights, civic culture, and republicanism are some of Arendt's concepts, the realization of which is set on the horizon of Brazilian society, aiming at the strengthening of our democracy.

KEYWORDS: Society. Politics. Public space. Democracy. Citizenship.

\footnotetext{
${ }^{*}$ Licenciado em Filosofia pela Pontifícia Universidade Católica de Goiás, Doutor em Educação pela Universidade Federal de Goiás, com estágio na Université Saint-Louis, de Bruxelas. Professor Adjunto do Centro de Ensino e Pesquisa Aplicada à Educação, onde atua no Programa de Pós-Graduação em Ensino na Educação Básica. Área de atuação: Filosofia da Educação. E-mail: evandsonpaivaferreira@gmail.com.
} 
O século XXI herda do século anterior questões que, mesmo diante do grande avanço tecnológico e da grande produção de riqueza material e simbólica, a humanidade ainda se põe como uma questão: a constituição do mundo coletivo como espaço público, espaço da pluralidade. Nesse sentido, a obra de Hannah Arendt se apresenta como atual e necessária. Num momento em que grandes contingentes de populações vagam pelo mundo, atravessam mares, põem suas vidas em risco, a fim de garantir a própria vida; num momento em que o mundo vê ressurgir discursos e práticas fascistas, que pareciam ter ficado no passado, sem dúvida, as reflexões de Arendt ganham nova vitalidade e nos provocam a pensar a condição humana atual, notadamente a brasileira, ainda tão cheia de contradições e desafios.

Sua obra nasce do modo singular como interrogou os acontecimentos em que se viu implicada, como a II Guerra e o totalitarismo. Momentos da história em que, para Arendt, a verdade e a mentira foram escamoteadas e transformadas em seu contrário, e o espaço público, assim como a liberdade pública, foram reduzidos ao estado pré-civilizado. Nesse sentido, o conjunto de sua obra se centrou em temas caros ao século XX, como o totalitarismo, a revolução, a condição humana, a violência, o poder, os direitos humanos. Arendt foi uma pessoa que "atravessou e interagiu com as catástrofes políticas, os desastres morais e os surpreendentes desenvolvimentos das artes e das ciências no século XX” (LAFER, 2008, p. 294).

Tal como Goethe faz com sua personagem Wilhelm Meister, também podemos dividir a vida de Arendt em Os anos de aprendizado e Os anos de peregrinação. O primeiro é marcado por uma profunda formação clássica. Ainda na adolescência, Arendt estudou grego e latim, o que permitiu uma maior familiaridade com os textos e a cultura dos gregos e romanos. Estudou Kant aos dezesseis anos e teologia aos dezessete. Em 1924 ingressou na universidade, terminando o doutorado em 1929, defendendo tese sobre Santo Agostinho. Foi durante os anos de estudante universitária, com pouco mais de dezoito anos, que entrou em contato com Heidegger, estabelecendo com ele uma relação que foi muito além dos textos e das aulas. Sobre o impacto de suas aulas, chegou a afirmar que com Heidegger "o pensamento tornou a ser vivo, ele faz com que falem tesouros culturais do passado considerados mortos e eis que eles propõem coisas totalmente diferentes do que desconfiadamente se julgava. Há um mestre; talvez se possa aprender a pensar" (ARENDT, 2008, p. 279-280). Essa relação só fora abalada no início dos anos 1930, devido à simpatia que Heidegger tinha pelo nazismo.

Não obstante as diferenças de suas filosofias e posturas políticas, Lafer pensa que Arendt é tributária de Heidegger quanto à concepção da função da linguagem como preservação e 
revelação. Estaria aí a origem de seu interesse pela literatura, pela poesia. Arendt só fez uma crítica explícita ao pensamento heideggeriano no período final de sua vida.

\begin{abstract}
A Heidegger Hannah Arendt deve sua visão da relação entre o ser e a temporalidade, que é o que explica o seu entusiasmo por $O$ ser e o tempo. Não aceitava, no entanto, a preocupação exclusiva de Heidegger com a história do ser, que o obnubilava para a história humana e, portanto, para um existencialismo aberto, como o de Hannah Arendt em relação a temas como os da comunidade, do diálogo, da amizade, da pluralidade, da natalidade e da ação. Entretanto, só se dispôs efetivamente a fazer uma crítica profunda a Heidegger - sobretudo ao segundo Heidegger, cuja rejeição da vontade, no entender de Hannah Arendt, o impedia de perceber as possibilidades da política e da ação - naquilo que veio a ser The life of the mind, mais precisamente em 1974, quando reviu os textos de suas "Gifford lectures" e estava certa de que Heidegger, aos 85 anos, velho e próximo da morte, não mais a leria. (LAFER, 2008, p. 297)
\end{abstract}

Outras influências intelectuais se fizeram presentes na vida universitária de Arendt e nos ajudam a compreender o zeitgeist do início do século XX europeu e a constituição do pensamento arendtiano. Karl Jaspers é sem dúvida uma dessas grandes influências e pode ser considerado seu segundo mestre. Husserl, o criador da fenomenologia, foi o orientador de doutorado de Jarpers, cujo tema foi O conceito de amor em Santo Agostinho. Sobre a relevância filosófica do pensamento juasperiano, Arendt presta uma homenagem em Homens em tempos sombrios (ARENDT, 2008, p. 80-104), discutindo os conceitos de humanidade e cidadania mundial desse autor. Segundo Lafer, Jaspers foi também uma pessoa que, pela maneira corajosa como se pôs diante do irracionalismo nazista, permitiu a Arendt se reconciliar com a tradição germânica, que apesar de ser judia, fazia parte tradição cultural alemã.

Arendt viveu seus primeiros anos de formação numa Alemanha de efervescência cultural e filosófica. Pensadores como Hartmann, Husserl, Cassirer e Heidegger são exemplos da grande riqueza e agitação dos meios intelectuais alemães. "Hannah Arendt é, sem dúvida nenhuma, produto e confirmação dessa efervescência e criatividade.” (LAFER, 2008, p. 298) Ela estudou numa universidade alemã onde se cultivava o estudo da filosofia, em especial da nova filosofia criada por Husserl, a fenomenologia. A essa filosofia Arendt deve seu método, cujo ponto de partida do pensamento é a palavra, cuja hermenêutica não se perde em abstrações conceituais, mas ajudam a esclarecer os elementos-chave dos fenômenos políticos, dos quais se ocupa Arendt: autoridade, revolução, violência, força, liberdade. O pensamento arendtiano se caracteriza por iluminar o passado, recuperando a 
historicidade das percepções passadas, e esclarece o presente, contudo deixando o pensamento aberto, sem determinismos.

Segundo Cruz,

\begin{abstract}
A experiência epistemológica do confronto com a realidade desenvolveu em Hannah Arendt um aptidão especial para pensar o geral e seu significado a partir de situações concretas. Daí a originalidade na qual se fundiram no seu percurso o saber da filosofia alemã e o olhar ensejado por sua inserção no mundo histórico-social e pelas vicissitudes de sua vida, no trato de temas e na reelaboração de categorias como a liberdade, a mentira, a violência, o imperialismo, a autoridade, a desobediência civil, a revolução, o poder. (CRUZ, 2009, p. 02).
\end{abstract}

Para Arendt, a via contemplativa não se pôs como possibilidade, uma vez que a questão judaica a obrigou a se confrontar com a realidade política do antissemitismo. "O pensamento de Hannah Arendt nasce do encontro com a experiência da perseguição nazista à qual sua vida foi submetida" (CRUZ, 2009, p. 02). Embora não tivesse temperamento para a vida pública, dedicou-se à militância na política judaica. As suas posições iam, muitas vezes, contra o que acreditavam os sionistas, assim como contra certas ações políticas do governo de Israel, como aconteceu no caso do polêmico livro Eichmann em Jerusalém, em 1963. Tratava-se de um livro, escrito a partir de uma série de reportagens que Arendt fizera para a revista New Yorker do julgamento de Adolf Eichmann, nazista capturado na Argentina, onde vivia clandestinamente. Nesse livro, ela analisa a banalidade burocrática do mal, o que chamou de banalidade do mal, criticando não apenas a banalidade do personagem Eichmann, "um cidadão respeitador das leis" (ARENDT, 1999, p. 152), mas também a conduta das lideranças judaicas na Europa. Tal conduta contribuiu para um número maior de vítimas no holocausto (ARENDT, 1999, p. 141142). Sua crítica teve como consequência um isolamento da comunidade judaica, o que não significou que Arendt tenha se desinteressando por esta comunidade.

Sua experiência de vida como judia num país que adotou políticas antissemitas, seus anos de peregrinação, como refugiada apátrida são elementos que orientaram e deram forma ao seu pensamento filosófico (LAFER, 2008, p. 306). Não é possível falar em espaço público, república, direitos humanos, cidadania, sem que uma de nossas referências não seja Arendt. Uma intelectual que não acreditava na inevitabilidade da revolução, mas na criatividade e espontaneidade dos movimentos políticos. A rebelião húngara, a revolução cubana, a revolução portuguesa, o movimento negro no sul dos Estados Unidos, o movimento estudantil dos anos 1960, eram vistos por ela como exemplos dessa espontaneidade. "Cartilhas sobre 'como fazer 
uma revolução' em um passo a passo progressivo, da discordância à conspiração, da resistência ao levante armado, baseiam-se todas na noção enganosa que as revoluções são "feitas"' (ARENDT, 2009b, p. 65). Daí sua crítica à violência, muitas vezes confundidas com poder, e a uma visão sui generis de como começa e do que é um processo revolucionário.

O pensamento político arendtiano retorna continuamente à pólis grega clássica, indo ao encontro de uma experiência política ímpar na história da humanidade, vendo nela a possibilidade de criticar a tradição do pensamento político e, ao mesmo tempo, de postular a criação de uma nova tradição. A “exemplaridade” da pólis clássica está no fato de ter realizado, em sua opinião, uma verdadeira política e um autêntico espaço público. Tal feito só se repetiria, para Arendt, em alguns poucos eventos históricos, como na Revolução Francesa, na Primavera de Praga, na Comuna de Paris e com os sovietes durante a Revolução de 1917.

Segundo Francisco (2008, p. 92)

[...] a pólis grega clássica assumirá nesse pensamento o sentido forte de paradigma a partir do qual se pensará e se julgará criticamente sejam as formas ulteriores de organização política, sejam as próprias categorias filosóficas produzidas em simultaneidade àquelas. Será, portanto, a medida com a qual aferir os graus de deformação das diferentes organizações políticas dos homens ao longo da história.

A compreensão que Arendt tem da pólis grega é uma importante chave de leitura para adentrarmos e entendermos os vários elementos da sua singular filosofia política. Não há em seu pensamento uma transferência anacrônica de instituições políticas gregas para a modernidade, mas a procura de uma arché, da origem da criação da política, da constituição de sua natureza e sentido. Há uma busca também de outras categorias que possibilitem a análise da política, tal como ela se apresenta com os modernos ${ }^{1}$. Para Arendt, os desastrosos eventos do século XX, os quais viu de perto, eram um desafio ao pensamento político, e somente novas categorias dariam conta dessa análise. "O se alojar na perspectiva grega da política tem esse sentido para a autora. Mas sua expatriação, por mais paradoxal que soe, não deixa de fazê-la profundamente filha de seu tempo" (FRANCISCO, 2008, p. 93).

Importante destacar o fato de que, mesmo sendo uma filósofa erudita e profundamente conhecedora da cultura helênica, não produziu uma obra específica sobre a política grega. $\mathrm{O}$

\footnotetext{
${ }^{1}$ Vários críticos irão afirmar que o modo como ela faz esse retorno à pólis grega é uma das fragilidades de seu pensamento. Habermas afirma que há uma construção de imagem da pólis, fazendo dela a essência do político, construindo "dicotomias conceituais rígidas 'público' e 'privado', Estado e economia, liberdade e bem-estar, atividade político-prática e produção, não aplicáveis à moderna sociedade burguesa e ao Estado moderno" (HABERMAS, 2001, p. 109).
} 
estudioso de sua obra encontra ao longo de diferentes textos análises do que foi a vida política grega, com suas instituições e categorias. Faz uma história da filosofia em que clássicos e modernos se encontram a todo o momento, procurando chamar atenção para as degenerações da vida política grega. Arendt afirma que há uma tradição do pensamento político, que não obstante os vários filósofos que trataram do assunto ao longo da história pode-se situar sua arkhé em três filósofos gregos, Sócrates, Platão e Aristóteles, os representantes da "opinião grega"; filósofos cujo pensamento - mesmo quando criticavam a política grega - está visceralmente ligado à vida da pólis clássica. Nela está o sentido de suas filosofias políticas. Dos três, é certo que foi Aristóteles o que mais influenciou o pensamento arendtiano.

Outra referência fundamental para a caracterização da pólis é Homero. Os textos de Aristóteles foram escritos no século IV a.C., período em que a pólis começava a deixar de ser o centro do universo político grego. Já os textos de Homero foram escritos no período arcaico, no século VIII a.C. Cada um dá testemunho de um momento da formação desse universo cultural. Da parte de Homero veem-se as origens e razões que fazem dos gregos os criadores do espaço público, sua autorrepresentação. Já em Aristóteles é possível observar a pólis plena, madura, no auge do desenvolvimento histórico, capaz de pôr para si as questões relativas aos fundamentos da vida coletiva.

Sobre a importância de Homero, "educador da Grécia”, aquele que melhor nos ajuda a conhecer a constituição daquele universo cultural, assim se expressou Jaeger (2001, p. 84):

\footnotetext{
[...] acima do elemento da raça e do povo, que só podemos apreender da maneira racional e intuitiva, e que se conserva com rara imutabilidade através das mudanças históricas do espírito e da fortuna, não podemos esquecer a influência histórica incalculável que o mundo humano plasmado por Homero exerceu sobre todo o desenvolvimento histórico posterior da sua nação. Nele, pela primeira vez, o espírito pan-helênico atingiu a unidade da consciência nacional e imprimiu o seu selo sobre toda a cultura grega posterior.
}

Em Homero se encontram experiências que permaneceram na cultura helênica e ajudaram na criação do sentido da vida política da pólis clássica. Arendt deixa claro que seu interesse não é procurar pelas causas históricas que originaram a pólis grega, mesmo porque, na lógica de seu pensamento, não é apenas um conjunto de fatos que explicam o surgimento ou não desta ou daquela instituição, mas a ação criativa dos homens no espaço público. Sua filosofia política se ocupa em pensar a dimensão criadora da ação humana, cujo potencial pode transcender os mais variados determinismos, como será mostrado adiante. A autora considera A oração fúnebre, de Tucídides, como o documento que revela a motivação, a raison d'être da 
fundação da pólis, bem como o seu significado na visão daqueles que nela viviam. Nesse texto, Péricles, ao distinguir o modo de ser do povo ateniense, destaca o compromisso da pólis democrática com o espaço público.

Segundo a filósofa, a motivação da criação da pólis está na intenção de garantir à ação humana e a seu discurso uma perenidade, uma permanência, tal como ocorria com a ação heroica, narrada pela poesia arcaica. Na esfera pública da pólis, a ação não seria mais louvada e imortalizada pelos poetas, mas pelo espaço público, lugar da visibilidade, da ação e do discurso.

\begin{abstract}
A rigor, a polis não é a cidade-estado em sua localização física; é a organização da comunidade que resulta do agir e falar em conjunto, e o seu verdadeiro espaço situase entre as pessoas que vivem juntas com tal propósito, não importa onde estejam. "Onde quer que vás, serás uma polis": estas famosas palavras não só vieram a ser a senha da colonização grega, mas exprimiam a convicção de que a ação e o discurso criam entre as partes um espaço capaz de situar-se adequadamente em qualquer tempo e lugar. Trata-se do espaço da aparência, no mais amplo sentido da palavra, ou seja, o espaço no qual eu apareço aos outros e os outros a mim; onde os homens assumem uma aparência explícita, ao invés de se contentar em existir meramente como coisas vivas ou inanimadas. (ARENDT, 2009a, p. 211).
\end{abstract}

Francisco (2008, p. 96) afirma que todo estudioso da obra de Hannah Arendt deve ter sempre em mente essa concepção sobre a origem e a razão de ser da pólis e da vida política, para melhor compreender sua noção de espaço público. Assim, a pólis fora fundada com "o propósito de mimetizar o campo de batalha troiano e a função imortalizadora do poeta épico". Troia, com sua experiência de guerra, tornou possível a seus cidadãos a participação em uma esfera exterior à vida íntima do lar. É desse modo que Arendt nos mostra como teria sido criado o espaço público ${ }^{2}$ e a vida política, lugar de realização de atos grandiosos, de individualização ${ }^{3}$, de glória e imortalidade.

Toda atividade realizada em público pode atingir uma excelência jamais igualada na intimidade; para a excelência, por definição, há sempre a necessidade da presença de outros, e essa presença requer um público formal, constituído pelos pares de indivíduo; não pode ser a presença fortuita e familiar de seus iguais ou inferiores. (ARENDT, 2009a, p. 58).

\footnotetext{
2 "Desde as formas mais arcaicas das cidades, no fim do século VIII e já em Homero, esboçam-se correlativamente, um dependendo do outro e articulando-se com ele, os domínios do que pertence ao comum, ao público, e do que pertence ao particular, ao próprio: to koinón e to ídion. O comum abarca todas as actividades, todas as práticas que devem ser partilhadas, ou seja, que não devem ser o privilégio exclusivo de ninguém, nem indivíduo, nem grupo nobiliário, e nas quais é o que não tem que ser partilhado e não diz respeito a ninguém" (VERNANT, 1988, p. 32). 3 Vernant (1988) nos lembra que quando falamos em indivíduo na Grécia antiga, este conceito não pode ser confundido com o indivíduo interior, tal como o concebemos desde o período da filosofia helenista.
} 
A pólis resolveria a questão da fragilidade e futilidade da ação humana, pois cria um corpo permanente de homens que formam um espaço onde a ação e o discurso podem ser vistos e ouvidos. Nele a memória é garantida, podendo ser transmitida às futuras gerações. Se entre os troianos a "ação" era esquecida ${ }^{4}$, pois não deixava um "produto", na pólis, a própria comunidade é que cultiva a memória coletiva, guardando-a como um patrimônio de todos. Nesse sentido, para Arendt, a origem da política não está na satisfação das necessidades materiais, necessidade de sobrevivência, mas na intenção de mostrar que o homem é o único ser da natureza capaz de criar e dar sentido a um mundo que transcende a vida biológica. Nas palavras de Francisco (2008, p. 108), “para Arendt, a ‘ação' e o ‘discurso' serão as atividades centrais da vida política e da esfera pública. Estar unido ao outro na modalidade da ação e da palavra é a única forma de vida adequada para homens, a única que lhe confere uma existência que pode ser chamada verdadeiramente 'humana"'.

O conceito de espaço público é constituído a partir da ideia do que é política. Arendt a entende como uma dimensão da vida humana que se realiza quando os homens formam um “nós”, uma unidade que se faz na convivência plural. Mas Arendt, contrariando a compreensão moderna de política, vai além, e afirma que a política é uma categoria que deve ser pensada separada da lógica econômica e social. Com isso, ela vai de encontro à teoria liberal, visto que, no seu pensamento, a ideia de uma esfera formada por indivíduos que afirmam e defendem interesses privados, negam radicalmente esse "nós" que é a vida política.

Sua crítica à modernidade vai nesse sentido, de mostrar a despolitização da esfera pública, e que a sociedade passou a se caracterizar, como afirma Telles (1990, p. 33) por indivíduos atomizados, que, sem noção de um mundo comum, se desinteressam pelo que é público, não se sentem responsáveis perante o mundo; "para esse indivíduo, o outro pouco importa e pouco conta, sua existência ou não existência não faz a menor diferença."

A era moderna é caracterizada pela alienação do homem em relação ao mundo, alienação compreendida por Arendt num duplo sentido. Houve um abandono do homem em relação à Terra, tanto em direção da conquista do universo físico, quanto na direção rumo ao eu interior. A autora indica três eventos históricos que simbolizam esse abandono do mundo: a chegada dos europeus ao Novo Mundo, a invenção do telescópio e a Reforma Protestante. A conquista da América foi responsável pela ampliação do espaço físico e diminuição das distâncias; o telescópio possibilitou ao homem lançar o olhar para além das fronteiras da Terra;

\footnotetext{
${ }^{4} \mathrm{O}$ herói dependia da visibilidade e publicidade para que sua excelência fosse reconhecida. Para o herói a vida só é completa se permanece imortal, na memória de seus grandes feitos.
} 
e a Reforma rompeu com a tranquilidade espiritual do homem europeu e deu origem a esse tipo de alienação no eu interior.

\begin{abstract}
Aos olhos dos seus contemporâneos, o mais espetacular dos três eventos deve ter sido a descoberta de continentes desconhecidos e de oceanos jamais sonhados; o mais inquietante deve ter sido a irremediável cisão do cristianismo ocidental através da Reforma. Com o inevitável desafio à própria ortodoxia e a imediata ameaça à tranqüilidade espiritual dos homens; e sem dúvida o menos percebido de todos foi a introdução, no já sortido arsenal de utensílios humanos, de um novo instrumento, inútil a não ser para olhar as estrelas, embora fosse o primeiro instrumento puramente científico a ser concebido. (ARENDT, 2009a, p. 261).
\end{abstract}

Para Arendt, na modernidade a esfera pública despolitizada fez com que a vida ficasse reduzida à satisfação dos imperativos da necessidade, cabendo ao sistema político satisfazê-los, numa relação de promiscuidade com a economia. O empobrecimento da esfera pública faz dela o lugar da administração burocrática, tecnicista, preocupada em atender às exigências das necessidades. O que na tradição ocidental fora de responsabilidade da economia, no sentido de atividades domésticas, do mundo privado do oíkos, passou a fazer parte da esfera pública. Arendt vê nessa transposição o fim da fronteira que separava o mundo público do mundo privado, surgindo uma nova esfera, a social.

Arendt afirma, em $A$ condição humana, que é na esfera social que os homens orientam suas ações com o intuito de satisfazer suas necessidades, desprezando a sociabilidade política, em favor do trabalho, sendo esta categoria o que vai garantir a vida associativa. Sem dúvida esse é um ponto da teoria arendtiana que desperta muitas críticas, pois a autora é acusada de ignorar o caráter político do trabalho. Por isso é preciso estar atento e seguir os seus argumentos, vendo que há uma lógica interna preocupada em ser coerente. Para ela, se tradicionalmente o trabalho fazia parte da vida privada, na modernidade ele é o que dá sentido e ordem à vida social, num tipo de sociabilidade em que o homem não é mais que produtor e consumidor. Arendt critica de modo radical essa nova esfera, pois nela o trabalho não pode promover a sociabilidade que a política exige, e priva o homem de um mundo compartilhado de significados. E, continua, faz com que a subjetividade dos indivíduos seja medida pelo mundo das coisas, impossibilitando a experiência da realidade mundana por meio da fala e da ação. Enfim, se é na pluralidade, na ação compartilhada, na realidade dialógica que Arendt irá alicerçar a noção de esfera pública, por coerência não poderá pensá-la a partir das categorias modernas. Há um caminho interpretativo original que leva a autora a utilizar em seus textos 
categorias incomuns, únicas, tais como: promessa, perdão, felicidade pública. Termos que deixam claro sua fidelidade, sem mimetismo, ao pensamento político clássico.

A esfera pública arendtiana é caracterizada pelo agón, sua natureza política é disputa entre sujeitos coletivos, e é o agir e o falar de tais sujeitos que a constitui como espaço político. É na esfera pública, lugar agonístico, que se formam as opiniões e as inter-relações das ações, lugar para a possibilidade do entendimento e do consentimento público, lugar também para o dissenso, para a diversidade de opiniões. Importante frisar que a diversidade das falas na esfera pública arendtiana não se refere, como fazem os pós-modernos, em achar que qualquer discurso é válido. A diversidade das falas tem o sentido de garantir aos isónomoi a isopsephía, um mesmo peso para cada discurso. É a diversidade que garante a pluralidade do discurso, a realidade dialógica, indo contra a tendência de massificação e homogeneidade próprias da esfera social. Arendt tem o cuidado em distinguir pluralidade de discurso de conflito. Este faz parte da vida social e não da vida política, pois tornaria impossível a pluralidade das ações e das falas, uma vez que a natureza do conflito está implicada em defender os interesses individuais.

\footnotetext{
A pluralidade humana, condição básica da ação e do discurso, tem duplo aspecto de igualdade e diferença. Se não fossem iguais, os homens seriam incapazes de compreender-se entre si e aos ancestrais, ou de fazer planos para o futuro e prever as necessidades das gerações vindouras. Se não fossem diferentes, se cada ser humano não diferisse de todos os que existiram, existem ou virão a existir, os homens não precisariam do discurso ou da ação para se fazerem entender. (ARENDT, 2009a, p. 188).
}

A esfera social é uma criação da modernidade, tendo na lógica do privado o guia para o mundo público, sendo seu fim último a satisfação das necessidades individuais. A vida coletiva passa a ser norteada pela busca da satisfação dessas necessidades, submetida aos interesses materiais. Nesse tipo de sociabilidade os homens só se reconhecem enquanto participantes de grupos, que por sua natureza de interesses, se excluem, não podendo ocupar ao mesmo tempo um espaço público. Nessa sociabilidade o diálogo é impossível, pois há o conflito, o choque de interesses na satisfação das necessidades que cada grupo priorizou, e não a discussão política. A fala e a ação são dispensáveis, pois na busca de satisfação de interesses dos grupos, o que dá sentido à existência comum é a ação atomizada; os homens são vistos não pelo que fazem, pensam ou dizem, mas pelo lugar que ocupam na hierarquia social.

Outro aspecto do surgimento da esfera social está ligado às transformações ocorridas no século XX e dizem respeito ao surgimento das massas e da conversão do cidadão em 
consumidor. As massas são o resultado do caráter propriamente apolítico da modernidade, e exemplificam um momento da história em que um grande número de pessoas parece partilhar o mesmo limbo impessoal de convicções não refletidas e acatadas silenciosamente. Arendt chama atenção para o fato de que essa homogeneidade de não-pensamento não é privilégio de uma classe específica, mas de todas elas, fazendo do homem um exilado de qualquer representação política normal. Um mundo guiado por valores do mundo privado cria uma sociedade em que predomina o conformismo e o isolamento, um tipo de mundo em que as pessoas não agem, mas se comportam, cumprem prescrições estabelecidas por uma forma burocrática de governo, o governo de "Ninguém". Na sociedade de massas o cidadão é transformado em cidadão-consumidor, e o único sentido que partilha com os outros indivíduos, todos juntos nesse isolamento coletivo, refere-se às necessidades biológicas, sem as quais não é possível a sobrevivência da espécie.

A ação política, ao contrário, tem como razão de ser a liberdade, a felicidade pública e o sentido da ação em vista do coletivo. É por ser a expressão da condição de liberdade do homem, que Arendt diz que a ação é caracterizada pela espontaneidade, expressando a capacidade humana de criar e fundar realidades políticas radicalmente outras. Arendt não partilha da crença moderna de que há uma racionalidade capaz de dominar e orientar a ação humana sobre a sociedade. No seu pensamento parece não ser a certeza racional (epistéme), mas a opinião partilhada (dóxa) que deve orientar o plano da ação, assim como não há uma teoria da revolução, mas criação histórica, o inesperado. É na esfera pública que os homens encontram o lugar privilegiado da criação, do agir desinteressado, tendo como télos, unicamente a responsabilidade pelo destino comum.

A ação na esfera pública se baseia não nos mores individualistas, mas em outra moralidade, sustentada na razão pública, ou seja, nos interesses comuns que conduzem ao diálogo e à ação. É a fala pública, e não o marketing político, confrontada com outras falas, avaliadas e julgadas, que fazem da esfera pública o lugar do livre diálogo. O direito dos homens se expressarem livremente no confronto de ideias é garantido pela igualdade, um fato jurídico, próprio da vida política.

$\mathrm{Na}$ ação e no discurso, os homens mostram quem são, revelam ativamente suas identidades pessoais e singulares, e assim apresentam-se ao mundo, enquanto suas identidades físicas são reveladas, sem qualquer atividade própria, na conformação singular do corpo e no som singular da voz. Esta revelação de "quem", em contraposição a "o que" alguém é - os dons, qualidades, talentos e defeitos que alguém pode exibir ou ocultar - está implícita em tudo o que se diz ou faz. [...] Esta qualidade 
reveladora do discurso e da ação vem à tona quando as pessoas estão com outras, isto é, no simples gozo da convivência humana, e não "pró" ou “contra" as outras. Embora ninguém saiba que tipo de "quem" revela ao se expor na ação e na palavra, é necessário que cada um esteja disposto a correr o risco da revelação... (ARENDT, 2009a, p. 192).

Pela igualdade há a emergência das opiniões que, pela visibilidade do espaço público, mostram a força política dos cidadãos e interferem nas decisões políticas. Arendt afirma que é na esfera pública que o poder é gerado, e é a manifestação da potencialidade humana de interação e diálogo. Em Sobre a violência (2009b), a autora faz a distinção entre poder e violência. Onde não há mais poder, isto é, quando desaparece a ação em concerto, aparece a violência, cuja natureza instrumental nega o espaço público e a isonomia dos cidadãos. Numa época em que a democracia é instrumentalizada e reduzida a meros mecanismos burocráticos de gestão, “o domínio de Ninguém”, “tirania sem tirano” (ARENDT, 2009b, p. 101), a autora insiste na ideia de que o poder se origina nas ações comuns dos homens na esfera pública, recusando qualquer confusão com um caráter instrumental ou estratégico.

\begin{abstract}
O poder só é efetivado enquanto a palavra e o ato não se divorciam, quando as palavras não são vazias e os atos não são usados para violar e destruir, mas para criar relações e novas realidades. [...] É o poder que mantém a existência da esfera pública, o espaço potencial da aparência entre homens que agem e falam. A própria palavra, como o seu equivalente grego, dynamis, e o latino, potentia, com seus vários derivados modernos, ou o alemão Match (que vem de mögen e möglich, e não de machen), indicam seu caráter de "potencialidade". O poder é sempre, como diríamos hoje, um potencial de poder, não uma entidade imutável, mensurável e confiável como a força. Enquanto a força é a qualidade matural de um indivíduo isolado, o poder a existir entre os homens quando eles agem juntos, e desaparece no instante em que eles se dispersam. [...] Todo aquele que, por algum motivo, se isola e não participa dessa convivência, renuncia ao poder e se torna impotente, por maior que seja a sua força e por mais válidas que sejam suas razões. (ARENDT, 2009a, p. 212-213).
\end{abstract}

Arendt não pensa a democracia no sentido de funcionamento, de boa gestão das instituições, nem a entende como um regime em que as políticas públicas são eficazes, atendendo adequadamente as demandas sociais. Ela destaca que tal "eficiência" pode ser encontrada em regimes não democráticos. Sua teoria sobre a democracia está fundada na noção de cultura cívica, isto é, a inserção na esfera pública de vários setores sociais, que sejam capazes de criar um novo tipo de mediação entre Estado e sociedade civil ${ }^{5}$. Usando o vocabulário grego,

\footnotetext{
${ }^{5}$ Arendt criticava os partidos políticos, pois via neles uma estrutura burocrática que inibia a participação política dos cidadãos. Em Sobre a violência ela afirma que "A transformação do governo em administração, ou das repúblicas em burocracias, e o desastroso encolhimento da esfera pública que as acompanhou têm uma longa e complicada história ao longo da época moderna; e esse processo tem sido consideravelmente acelerado durante os últimos cem anos por meio do surgimento das burocracias partidárias.” (ARENDT, 2009b, p. 102)
} 
podemos dizer que em Arendt existe a exigência de uma paideia que provoque nos homens uma mudança no modo como entendem e vivem a política.

O pensamento político arendtiano com sua noção de esfera pública, sua crítica à confusão quanto ao que é próprio do mundo público e do mundo privado, pode nos ajudar a pensar criticamente a realidade política brasileira. Para quem se propõe a estudar a democracia brasileira percebe que a noção de cultura cívica parece ser um dos pontos que inviabilizam a construção do espaço público no Brasil. Há no Brasil uma relação entre Estado e sociedade civil sem o suporte dessa cultura, de modo que as decisões políticas não são influenciadas pela participação política da sociedade, mas, segundo Nascimento (2008, p. 56), pela "habilidade de pechinchar dos setores sociais". É possível afirmar que no Brasil há uma cultura política que vê na sociedade civil apenas um cliente do Estado, situação paradoxal que confirma a contínua despolitização do cidadão, cuja ação está cada vez mais atomizada. Médicos sem fronteiras, restaurante cidadão, criança esperança, campanha do agasalho, parecem ser essas as únicas ações coletivas de que o cidadão está disposto a participar, e é assustador constatar isso, pois nenhuma delas propõe a criação de algo novo, de novas formas de sociabilidade. São ao mesmo tempo herdeiras de uma velha forma de caridade e portadoras de uma nova concepção de cidadania centrada na ação individual, um pouco mais do mesmo, usando outro vocabulário. É na esteira e para além da teoria política arendtiana que é possível pensar esse espaço público desfigurado e iluminar a concepções de cidadania presentes no discurso cotidiano e que, na maior parte das vezes, não passa de mera nomenclatura, sem qualquer conteúdo verdadeiramente político.

Olhando para a história da formação política brasileira, pode-se ver a dificuldade em estabelecer uma fronteira nítida entre a vida pública e a vida privada, de tal modo que o que seria próprio do espaço público sempre foi regido a partir da realidade doméstica. Isso determinou o modo como se dá a relação entre o Estado e o cidadão, marcada por um alto grau de clientelismo, fazendo de nossas instituições políticas meras prestadoras de favor. Não havendo a noção do "direito a ter direitos", temos um verticalismo nas relações sociais que diz a cada um quem ele é e o que ele pode a partir de seu status na hierarquia social.

Apesar desse tipo de cultura política, é possível destacar iniciativas de ações coletivas, as quais indicam a possibilidade de constituição de um espaço público no Brasil. Doimo (1995) afirma que a partir dos anos 1970 houve uma mudança nas práticas associativas, embora ainda tendo a lógica privada como diretriz. Contudo é nesse período que a esfera pública começa a ser ocupada pela sociedade civil, e novos atores aparecem na cena política. Surgem movimentos 
que lutam pelo direito à moradia, pela saúde pública, pelos direitos das mulheres, pela ecologia. O surgimento desses movimentos significou uma mudança importante na participação do cidadão na vida política, principalmente se levarmos em consideração o fato de tudo isso ter acontecido ainda sob regime ditatorial.

A década seguinte é marcada por uma maior organização da esfera pública, momento em que os movimentos da sociedade civil estabelecem relações mais próximas com o Estado. Embora a grande mobilização das Diretas já não tenha obtido o resultado desejado, mostrou uma nova disposição de participação popular. E ainda sobre os anos 1980, podemos destacar como a maior conquista desse período a promulgação, em 1988, da nova Constituição, fruto de longos debates e de luta de forças em que novos atores políticos puderam expressar todo seu poder de negociação.

Nos anos 1990 não houve grandes mudanças, existindo apenas o surgimento de organizações civis com novos formatos e propostas de intervenção. Elas vão além do formato de interlocução política com o Estado e passam a querer participar e influenciar na gestão da coisa pública. Essas organizações não apenas dizem quais são as necessidades da sociedade, mas também estão presentes durante a execução e avaliação das políticas públicas. Os novos atores políticos conseguem introduzir novos temas, de modo que, se até anos 1980 a educação, a habitação, a saúde etc. eram os temas emergentes, nos anos 1990 surgem temas como diversidade cultural, direitos do cidadão etc.

Diante do exposto é possível perceber que houve avanços e conquistas na participação do cidadão na esfera pública, mas a vida política brasileira tem muito a amadurecer. Ainda persiste a ausência de uma cultura cívica, isto é, uma ausência de valores políticos capazes de romper com o domínio da lógica privada sobre o mundo público e instituir uma cidadania ativa, um interesse coletivo pelo que é público. O cidadão não pode ser visto como um indivíduo isolado que tem sua cidadania confirmada quando suas necessidades materiais são satisfeitas. Tal compreensão do que é o cidadão vai contra a democracia, dando margem à exclusão e a desigualdade política. Ao contrário de tudo isso, a cidadania ativa, no sentido pensado por Arendt, exige a participação na esfera pública, sendo a presença do cidadão diante dos outros o que fundamenta a vida política.

Arendt nos mostra que a dimensão e a importância da esfera pública não são medidas pelo nível de atendimento das demandas dos vários grupos, mas pela capacidade de gerar civismo, de mobilizar os atores sociais, de incentivar o debate público. Assim, a esfera pública não é mercado político, balcão de negócios, lugar de competição entre grupos de interesses. Ela 
enfatiza que o conflito de interesses não cria uma cultura cívica, pois expressa atitudes não compartilhadas, e que o interesse particular de um determinado grupo só tem validade política quando passa a ser interesse de todos.

A realização da esfera pública, na perspectiva arendtiana, exige uma paideia democrática, uma formação para os novos valores de uma cultura cívica, para uma outra forma de sociabilidade, não apenas diferente da atual, mas radicalmente outra. Uma nova sociabilidade que ainda se defrontará com a herança da formação cultural brasileira, mas que pode ajudar na transição incompleta do autoritarismo à democracia. A desigualdade social, o racismo, a violência, o verticalismo nas relações sociais são limites postos à formação do espaço público no Brasil. Outro limite disfarçado de avanço é a transformação do substantivo cidadania em adjetivo, uma nova forma de escamotear o verdadeiro sentido político da cidadania, fazendo dela um selo que diz se o serviço prestado pelo Estado foi “eficiente" ou não. Escola cidadã, consumidor cidadão, transporte cidadão são os novos nomes do velho clientelismo e da prestação precária de serviços públicos. Com Hannah Arendt, a partir da radicalidade e rigor de seu pensamento, concluímos o texto destacando que só é possível qualquer mudança se a coletividade tomar para si a responsabilidade de tirar o véu que cobre a realidade e mostrar as contradições, os limites e as possibilidades da ação humana na constituição do espaço público.

\section{Referências}

ARENDT, Hannah. A condição humana. 10. ed. Rio de Janeiro: Forense Universitária, 2009a.

ARENDT, Hannah. Eichmann em Jerusalém. São Paulo: Companhia das Letras, 1999.

ARENDT, Hannah. Homens em tempos sombrios. São Paulo: Companhia das Letras, 2008.

ARENDT, Hannah. Sobre a violência. Rio de Janeiro: Civilização Brasileira, 2009b.

CRUZ, José Adelson da. O público, o privado e o direito a ter direito: notas sobre o pensamento da Hannah Arendt. Goiânia, 2009. 15 p. Notas de aula.

DOIMO, A. M. A vez e a voz do popular: movimentos sociais e participação política no Brasil. Rio de Janeiro: Relume-Dumará, 1995.

FRANCISCO, Maria de Fátima Simões. Homero como fonte da polis grega. In: CORREIA, A.; NASCIMENTO, M. Hannah Arendt: entre o passado e o futuro. Juiz de Fora: Ed. UJFJ, 2008, p. 90-110. 
HABERMAS, Jürgen. O conceito de poder de Hannah Arendt. vol. 15. São Paulo: Ática, 2001 (Coleção grandes cientistas sociais).

JAEGER, Werner. Paidéia: a formação do homem grego. 4. ed. São Paulo: Martins Fontes, 2001.

LAFER, Celso. Hannah Arendt: vida e obra. In: Homens em tempos sombrios. São Paulo: Companhia das Letras, 2008. p. 291-312.

NASCIMENTO, Mariângela. A esfera pública na democracia brasileira: uma reflexão arendtiana. In: CORREIA, A; NASCIMENTO, M. Hannah Arendt: entre o passado e o futuro. Juiz de Fora: Editora UFJF, 2008. p. 53-72.

TELLES, Vera. Espaço público e espaço privado na construção do social: notas sobre o pensamento da Hannah Arent. Tempo Social, v. 2, n. 1, 1990.

VERNANT, Jean-Pierre. O indivíduo na cidade. In: VEYNE, P. et. al. Indivíduo e poder. Lisboa: Edições 70, 1988. p. 25-44. 